|| Print ISSN: 2589-7837 || Online ISSN: 2581-3935 ||

International Journal of Medical Science and Diagnosis Research (IJMSDR)

Available Online at www.ijmsdr.com

NLM (National Library of Medicine ID: 101738824)

Original Research Article

Volume 6, Issue 1; January: 2022; Page No. 84-90

\title{
Umbilical Cord Coiling Index Sonographic Evaluation in its Relationship with Perinatal Outcome and Late Second Trimester
}

\author{
Dr. Balameenakshi' ${ }^{1}$, Dr. G. Yuvabalakumaran ${ }^{2}$ \\ Research Scholar ${ }^{1}$, Associate Professor ${ }^{2}$, \\ Department of Radiology ${ }^{1,2}$,
}

Vinayaka Missions Kirupanandha Variyar medical college, Salem ${ }^{1,2}$

Conflicts of Interest: Nil

Corresponding author: Dr. Balameenakshi

DOI: https://doi.org/10.32553/ijmsdr.v6i1.909

\section{Abstract:}

Objectives: To assess the relationship between perinatal results along with umbilical cord coiling index derived from sonographer solutions.

Study Design: This predictive research was executed in the OBG department of radiology at Vinayaka missions Kirupananda Variyar medical college and hospital of Medical Sciences, Salem, India from April, 2021 to September, 2021. Of the 60 patients included in the study, single pregnancies with direct vaginal / LSCS babies, regardless of equality, with active delivery from the second trimester to final pregnancy. From the results of the ultrasound, the "umbilical cord coiling index" was correlated and calculated with different perinatal criteria such as equivalence, gestational hypertension (PIH), gestational diabetes (GD) and 1 gestational age (in weeks), Delivery method and Apgar score. Fisher tests and Chi-squared were assist to determine the importance of the parameter findings.

Results: The current results of the ultrasound evaluation show that the UCI provides a significant correlation with hypocrite coils (UCI $>90 \%$ ), babies PIH (p-value $<0.05$ ), and GDM (p-value $0.044)$ Hypocoiled $(\mathrm{UCI}<10 \%)$ and Hypercoiled cords $(\mathrm{p}<0.05)$ were significantly related to the Apgar score ( $\mathrm{p}$ less than 0.05).

Conclusion: hypercoiled Coils or UCI $>90 \%$ is associated with IUGR and is part of primary perinatal results such as PIH and GDM. Both hypocoiled and hypercoied cords, and UCI $<10 \%$, linked to the Apgar score for the perinatal results, thus showing a greater correlation with the UCI index.

Keywords: Hypercoiling umbilical cord, Umbilical cord coiling index, Hypocoiling umbilical cord

\section{Introduction:}

The foetus's sustenance, growth, development, wellbeing, and survival are closely related to the umbilical cord (Mukunya et al., 2020). Regardless of its importance in helping the baby in the mother's womb, the cord is not protected against certain physiological issues such as torsion, kinking, compression, and traction, leading to the perinatal result of deleterious. Since vessels are the more unprotected sector of the anatomy of the fetus. The coils total number associated with a specific cord is at the starting days of the gestation phase (Krzyżanowska et al, 2020). 
The patterns underlying the development of coiling happen at the end of the third and second trimesters of pregnancy, which may be according to physiological obstruction of the cord and modulation of physiological changes in the cord during pregnancy's long duration. Typically, two umbilical arteries form a cylindrical helix around the umbilical vein, while three blood vessels run along with the helical fashions (Gupta et al, 2006). These fusions of the helical of the umbilical vessels are called the spiral course (Rana et al, 1995). The normal umbilical cord has one singular coil for every $5 \mathrm{~cm}$ of cord length (Predanic, 2005). Generally, the umbilical cord develops around 40 spirals in total, and there are straight portions, and in certain cases, there exists a reversal in the spiral direction under various segments within the umbilical cord (Edmonds, 1959). The coil typically has a 360-degree umbilical cord spiral course around Wharton's jelly (Khier \& Elghazaly, 2015). Abnormal index of the umbilical cord includes the umbilical cord and hypocoiled (less than 10 percent cord) and hypercoiled cods (more than 90 percent cord). The unusual umbilical cord index has been calculated to be associated with prenatal effects (Ezimokhai et al, 2001). -

The current research aimed to analyze the perinatal effects through indices of abnormal umbilical cord among the maternal sample population comprising of patients who are reaching their late second-trimester phase.

\section{Methods and Materials}

This is a systematic study executed in the field of Gynecology and Obstetrics at Medical Sciences Institute, Chennai, Tamil Nadu, Salem, India from April, 2021 to September, 2021. The clearance of the ethical committee was acquired from the ethics committee and Research Council of Institute. Sixty active labor patients during the second trimester of pregnancy, parities irrespective, who have single pregnancies with naturally arrived babies via the vaginal delivery/ LSCS, were involved in this study.

After isolating the baby's umbilical cord, the cord was cut close and tied to the baby as expected. The entire umbilical cord was assessed, involving the placental end of the cord and the length of the baby's umbilical stump. The total number of spirals or coils was calculated from the neonatal end from the cord of the placental end, and it was indicated in $\mathrm{cm}$.

Aloka SSD-1200 or SSD-2000 High Target Modules (Aloha, Tokyo, Japan) all ultrasound evaluations were carry out using a secondtrimester fetal morphology scan continuously equipped with a $5.0 \mathrm{MHz}$ curvilinear transducer. Views that are longitudinal at the umbilical cord level were acquired at the distance between the coils, and the highest magnification was estimated from the inner edge of the arterial wall to the next outer edge. UCI is described as the ratio of the normal distance between coil's two pairs. The clear photos were acquired perpendicular to the cord. First, ultrasound estimates of the intercoil distance (figure 1) were carried out between the three to two coils of the umbilical cord were made: (1) near the entrance to the fetal abdominal, (2) near the insertion of the placenta, and (3) both sites distance, In the cord middle (3). Then the UCI was decided by dividing the absolute coils total number divide by the total cord length in $\mathrm{cm}$.

$$
U C I=\frac{\text { Number of coils }}{\text { Total length of cord measured in } \mathrm{cms}}
$$

Later, at this time, perinatal factors such as ponderal index, Apgar score, meconium staining, and foetal weight were associated with UCI. As a result, the impact on perinatal results of umbilical vascular coiling was executed. Therefore, all kids and patients were take care until discharge from the hospital. 


\section{Results}

Among 60 women patients who were studied, the UCI findings reported that only 7 were hypercoiled, 8 with hypocoiled and the remaining 45 patients were normocoiled (Figure 1). In terms of parity, it was reported from parity outcomes that primiparous was reported among 31 and and multigravida were 29. In terms of age distribution among patients, it was observed that the majority $(60 \%)$ of the patients were within 18-25 years, with conditions of hypercoiled and hypocoiled cord was reported and prevalent in almost all the age group examined (Table 1).

Table 1: Correlation between mother age during labour versus UCI.

\begin{tabular}{|c|c|c|c|c|c|c|c|}
\hline \multicolumn{8}{|c|}{ Crosstab } \\
\hline & & & \multicolumn{3}{|l|}{ Age } & \multirow{2}{*}{ Total } & \multirow{2}{*}{$P$ value } \\
\hline & & & $18-25$ & $26-30$ & $31-37$ & & \\
\hline \multirow{6}{*}{$\begin{array}{l}\text { Coiling } \\
\text { index }\end{array}$} & \multirow[t]{2}{*}{ Hypercoiled } & Count & 3 & 2 & 2 & 7 & \multirow[t]{8}{*}{$\mathrm{P}=0.439$} \\
\hline & & $\%$ of Total & $5.0 \%$ & $3.3 \%$ & $3.3 \%$ & $11.7 \%$ & \\
\hline & \multirow[t]{2}{*}{ Hypocoiled } & Count & 4 & 3 & 1 & 8 & \\
\hline & & $\%$ of Total & $6.7 \%$ & $5.0 \%$ & $1.7 \%$ & $13.3 \%$ & \\
\hline & \multirow[t]{2}{*}{ Normocoiled } & Count & 29 & 13 & 3 & 45 & \\
\hline & & $\%$ of Total & $48.3 \%$ & $21.7 \%$ & $5.0 \%$ & $75.0 \%$ & \\
\hline \multirow{2}{*}{\multicolumn{2}{|c|}{ Total }} & Count & 36 & 18 & 6 & 60 & \\
\hline & & $\%$ of Total & $60.0 \%$ & $30.0 \%$ & $10.0 \%$ & $100.0 \%$ & \\
\hline
\end{tabular}

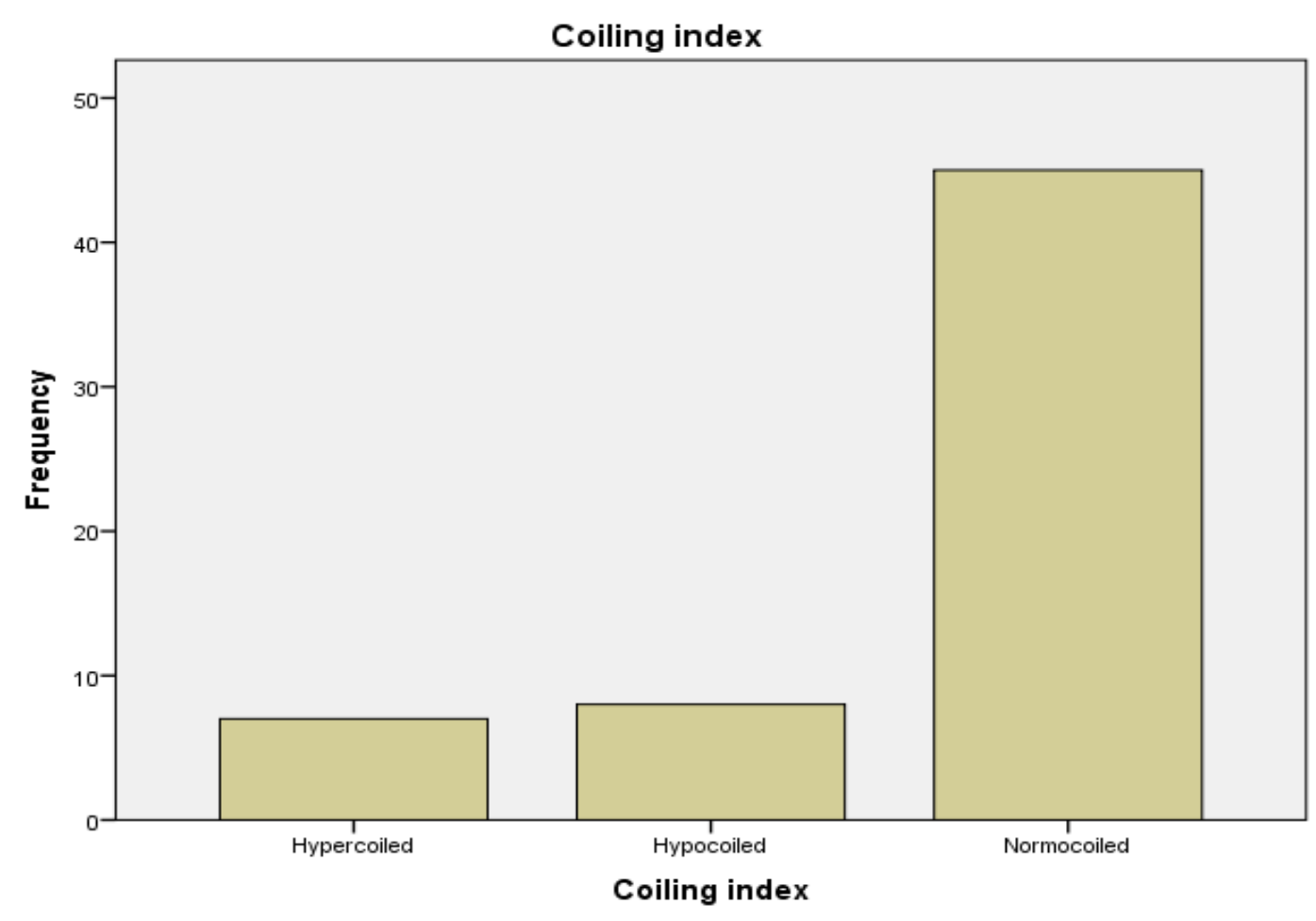

Figure 1: Distribution of UCI index 
As for the delivery mode of the results, 36 women were delivered naturally, and 24 women who showed signs of LSCS deliveries had evidence of fetal distress. In the current research, $<10 \%<0.06$, UCI was examined hypocoiling, and UCI $>90 \%$ was percentile at 0.48 , known as hypercoiling. PIH was found in 7 cases, which were hyper coil case (n-1) and hypocoiled (n-4). GDM cases were calculated in a ratio of 6 (n-2 per case) and most often occurred in the normocoiled, hypercoiled, and hypocoiled cases. The Apgar score at 1 minute of $<4$ was found in 31 cases, and $>4$ was found in 169 women cases.

Table 1 showed the relationship between perinatal results such as GDM and PIH. A UCI and hypercoiled of less than $10 \%$ associated with the Apgar score show a significant correlation with the list of sonographic results of the UCI index

Table 2: Correlation analysis between perinatal outcomes and UCI.

\begin{tabular}{|c|c|c|c|c|c|c|}
\hline \multicolumn{7}{|l|}{ Cross tabulation } \\
\hline & & \multicolumn{3}{|l|}{$\mathrm{UCI}$} & \multirow[t]{2}{*}{ Total } & \multirow{2}{*}{$\begin{array}{l}\mathrm{p} \\
\text { value }\end{array}$} \\
\hline & & Normocoiled & Hypocoiled & Hypercoiled & & \\
\hline \multirow[t]{2}{*}{ PARITY } & PRIMIPAROUS & 24 & 4 & 3 & 31 & \multirow[t]{3}{*}{.871} \\
\hline & MULTIGRAVIDA & 21 & 4 & 4 & 29 & \\
\hline \multicolumn{2}{|l|}{ Total } & 45 & 8 & 7 & 60 & \\
\hline \multirow[t]{2}{*}{$\mathrm{PIH}$} & YES & 2 & 4 & 1 & 7 & \multirow[t]{3}{*}{$.001 * *$} \\
\hline & $\mathrm{NO}$ & 43 & 4 & 6 & 53 & \\
\hline \multicolumn{2}{|l|}{ Total } & 45 & 8 & 7 & 60 & \\
\hline \multirow[t]{2}{*}{ GDM } & YES & 2 & 2 & 2 & 6 & \multirow[t]{3}{*}{$.044 * *$} \\
\hline & $\mathrm{NO}$ & 43 & 6 & 5 & 54 & \\
\hline \multicolumn{2}{|l|}{ Total } & 45 & 8 & 7 & 60 & \\
\hline \multirow{3}{*}{$\begin{array}{l}\text { GESTATIONAL } \\
\text { IN WEEKS }\end{array}$} & \begin{tabular}{l|l}
$<37$ WEEKS \\
\end{tabular} & 3 & 3 & 1 & 7 & \multirow[t]{4}{*}{.119} \\
\hline & 37-40 WEEKS & 33 & 5 & 5 & 43 & \\
\hline & $>40 \mathrm{WEEKS}$ & 9 & 0 & 1 & 10 & \\
\hline \multicolumn{2}{|l|}{ Total } & 45 & 8 & 7 & 60 & \\
\hline \multirow{2}{*}{$\begin{array}{ll}\text { MODE } & \text { OF } \\
\text { DELIVERY } & \end{array}$} & VD & 29 & 4 & 3 & 36 & \multirow[t]{3}{*}{.458} \\
\hline & LSCS & 16 & 4 & 4 & 24 & \\
\hline \multicolumn{2}{|l|}{ Total } & 45 & 8 & 7 & 60 & \\
\hline \multirow[t]{2}{*}{ APGAR SCORE } & Less than 7 & 3 & 6 & 4 & 13 & \multirow[t]{3}{*}{$.000 * *$} \\
\hline & More than 7 & 42 & 2 & 3 & 47 & \\
\hline \multicolumn{2}{|l|}{ Total } & 45 & 8 & 7 & 60 & \\
\hline
\end{tabular}






Figure 2: Graphical illustration indicating the perinatal outcomes and their distribution across UCI category

\section{Discussion}

The umbilical vessel by the spiral course was first recorded in 1521 by Berengarius. Arantius in 1564and Columbus later confirmed it in 1559. In 1600, Fabricius revealed the existence of the umbilical cords' left (sinistral) and right (dextral) helices (Edmonds, 1954). If the umbilical cord is constant randomly twists, both types of twists will have the same frequency. Despite this, many researchers point out that the majority of chords are leftwing twists (Lacro et al., 1987; Strong et al., 1998). The number of changes in the first three months is usually equal to the term cords. After that, the number of the total coil is between 0 and 40. Umbilical coiling seems to confer turgor to the umbilical cord, resulting in a strong producing cord, still manageable. When the penis retracts from the end of the fetus, the curvature of the penis indicates a long record of fetal development (Strong et al., 1998).

The coil is the 360-degree spiral course of the vessels of the umbilical. Umbilical cord index (UCI) is the number of the total coil divided by the total cord length in cm. Rana et al, (1995) have completed this frequency UCI distribution.

From the assessment of several works of literature written to date, various trials in the past have examined the primary regards of 
correlation to relationship between perinatal effects and UCI. In this review, some of the key UCI parameters assessed by sonographer results were taken into account by digitization. After comparing the UCI along with parity, it was found that there was no statistical importance between them. For example, pregnancies with high blood pressure and gestational diabetes mellitus (GDM) were primarily associated with the UCI assessment. For example, Diwakar et al, (2017) results show that abnormal cord coiling in the two types is non-coiling, and hyper coiling is more likely to occur in women with gestational diabetes, supporting our conclusions. In addition, in the case of hypertension induced by pregnancy, there is complete protection against uteroplacental circulation due to the lack of adequate invasion of trophoblastic into the maternal spiral arteries result in lower blood flow around to the placenta to placental dysfunction and vascular lack which negatively impact the development of fetus Change in blood flow. (Chillakuru et al., 2020) and its association with the hyper coiled cords lad to have a higher likelihood in its relationship impacts the umbilical venous blood flow. However, the association the limits of fetal development and between the hypercoiled cords could not be explained due to minimum cases as stressed by Nishio et al, (1999).

Gupta S et al. (2006) found lower Apgar scores on 107 umbilical cords and hypo coiled cords. Padmanabhan et al., reviewed 130 umbilical cords were examined, and Apgar scores were mainly low in the hypo coiled group (Strong et al., 1994).

In the current research, the UCI Apgar score of 5 min $<7$ was less than $10 \%$. Monique WM et al. focused on 885 cases and establish that the hypo coiling was relationship with lower Apgar scores (Monique et al., 2006). Gupta S et al. analyzed that Apgar Scores and analyzed 107 cords Children under 7 years of age have had lower UCIs than the children with Apgar scores $>7$ (Gupta et al., 2006). 130 umbilical cords and a group of hypo coiled were associated with less than 7 Apgar scores was found by Padmanabhan LD et al, (2001).

\section{Conclusion}

Based on UCI results and perinatal outcomes, unusual umbilical cord recording was linked with a fraction of negative perinatal effects such as PIH, GDM, and APGAR score. For UCI, more than $90 \%$ of hyper coiling is associated with limitations in fetal development. In this way, antenatal diagnosis of coiling index in the late second trimester or early assessment may be appropriate to diagnose efficacious fetal complications, which are at the problem and assist in further management.

\section{References}

1. Krzyżanowski A, Kwiatek M, Gęca T, Stupak A, Kwaśniewska A. Modern ultrasonography of the umbilical cord: prenatal diagnosis of umbilical cord abnormalities and assessement of fetal wellbeing. Medical science monitor: international medical journal of experimental and clinical research. 2019; 25:3170.

2. Mukunya D, Haaland ME, Tumwine JK, Tylleskar T, Nankabirwa V, Moland KM. "The cord is the child": meanings and practices related to umbilical cord care in Central Uganda. BMC pediatrics. 2020 Dec;20(1):1-9.

3. Gupta S, Faridi MMA, Krishnan J. Umbilical Coiling Index. J. Obstet Gynecol India. 2006;56(4):315-19.

4. Rana J, Ebert GA, Kappy KA. Adverse perinatal outcome in patients with an abnormal umbilical coiling index. Obst. Gynaecol. 1995;85(4):573-77.

5. Predanic M. Sonographic assessment of the umbilical cord. Ultrasound Rev Obstet Gynecol 2005; 5: 105-10.

6. Khier A, Elghazaly EA (2015). Correlation between the Umbilical 
Cord Morphology and Birth Weight in Full Term Sudanese Neonates (Doctoral dissertation, University of Gezira).

7. Ezimokhai M, Rizk DE, Thomas L. Abnormal vascular coiling of the umbilical cord in gestational diabetes mellitus. Archives of physiology and biochemistry. 2001 Jan 1;109(3):209-14.

8. Lacro RV, Jones KL, Benirschke K. The umbilical cord twist: origin, direction, and relevance. American Journal of Obstetrics and Gynecology. 1987;157(4):833-838.

9. Edmonds HW. The spiral twist of the normal umbilical cord in twins and in singletons. American Journal of Obstetrics and Gynecology. 1954;67(1):102-120.

10. Strong Jr. TH, Elliott JP, Radin TG. Noncoiled umbilical blood vessels: a new marker for the fetus at risk. Obstetrics and Gynecology. 1993;81(3):409-411.
11. Strong TH, Jarles DL, Vega JS, Feldman DB. The umbilical coiling index. Am. J. Obst. Gynecol Part I. 1994;170(1):29-32.

12. Chillakuru S, Velichety SD, Rajagopalan V. Human umbilical cord and its vessels: a histomorphometric study in difference severity of hypertensive disorders of pregnancy. Anatomy \& cell biology. 2020 Mar;53(1):68

13. Diwakar, R.K., Naik, M.M. and Jindal, M.M., 2017. Umbilical cord coiling: case report and review of literature. $B J R \mid$ case reports, p.20150152.

14. Nishio, J., Nakai, Y., Mine, M., Imanaka, M., \& Ogita, S. (1999). Characteristics of blood flow in intrauterine growth-restricted fetuses with hypercoiled cord. Ultrasound in Obstetrics and Gynecology: The Official Journal of the International Society of Ultrasound in Obstetrics and Gynecology, 13(3), 171-175. 